\title{
Plantas medicinales para tratar enfermedades primarias en tres comunidades tuahkas
}

\author{
José de la Cruz Meléndez Dixon
}

\section{INTRODUCCIÓN}

Este documento nos muestra resultados concretos sobre el uso medicinal que hacen de las plantas la comunidad tuahka: su preparación y aplicación. También provee información de los sitios en donde se puede encontrar estas plantas, su descripción y las temporadas de corte. Igualmente describe la diferencia, en cuanto a efectividad, entre la medicina tradicional y la occidental. Además de la preparación y aplicación de la medicina, nos brinda información acerca de la forma de proceder y los cuidados que se deben tener durante determinados períodos de curación.

\section{PLANTAS MEDICINALES PARA TRATAR DIFERENTES ENFERMEDADES PRIMARIAS}

En las comunidades indígenas tuahka existen diferentes plantas que son utilizadas para diversas enfermedades. Algunas de estas plantas provienen de culturas exógenas, y otras son utilizadas ancestralmente por nuestras comunidades, tales como las hojas y la raíces de albahaca, culantro, el zorrillo, pico de pájaro, cogollo de guanábana, leche de Chilamate, hojas de guarumo, corteza de guapinol, hojas de eucalipto, hojas de zacate de limón, corteza de guayaba, uña de gato, hojas de jocote, aceite de coyol, hojas angiosperma, el aceite de coco, aceite de pino, cogoyo y jugo de limón, quinina, corte de mango, raíces de limón, corteza de indio desnudo, fruta y tallo de cedro macho, corteza de querosín, orégano, hombre grande, corteza de nancite.

Estas plantas medicinales se preparan de diferentes maneras y para diversas enfermedades comunes, tales como: diarrea, vómitos, dolor de estómago, dolor de cabeza, tos, resfríos, parásitos, dolor de oído, dolor de muelas, mareo. A continuación presentamos 16 plantas medicinales con sus nombres (científico, mayangna, español), temporadas de corte y el sitio en donde se pueden encontrar. Se utilizan para tratar enfermedades primarias en las comunidades objeto de nuestra investigación, con sus respectivos nombres en español y mayangna.También se presentan las temporadas de corte, su nombre científico y donde pueden ser encontradas:

\begin{tabular}{|c|l|l|l|l|l|l|}
\hline \multicolumn{2}{|c|}{ Tipos de Plantas } & Enfermedades & Mayangna & $\begin{array}{c}\text { Nombre } \\
\text { científico }\end{array}$ & $\begin{array}{c}\text { Tamaño } \\
\text { (planta) }\end{array}$ & $\begin{array}{l}\text { Temporada de } \\
\text { corte }\end{array}$ \\
\hline $\mathbf{1}$ & $\begin{array}{l}\text { Eucalipto: } \\
\text { Son árboles de hasta 40 } \\
\text { metros de altura, corteza lisa } \\
\text { escamosa, hojas finas, y } \\
\text { aromáticas. }\end{array}$ & Tos y gripe. & - & Eucalyptus \\
$\mathbf{2}$ & $\begin{array}{l}\text { Zacate de limón: } \\
\text { Es una hierba de hojas verdes } \\
\text { alargadas, a veces teñidas } \\
\text { de rojo, que posee un olor } \\
\text { agradable a limón. }\end{array}$ & $\begin{array}{l}\text { Fiebre, asma yasta } 40 \\
\text { gripe. }\end{array}$ & Ti & $\begin{array}{l}\text { Cymbopogon } \\
\text { metros de altura. } \\
\text { Cicatrus }\end{array}$ & Perenne \\
\hline
\end{tabular}




\begin{tabular}{|c|c|c|c|c|c|c|}
\hline \multicolumn{2}{|r|}{ Tipos de Plantas } & Enfermedades & Mayangna & $\begin{array}{l}\text { Nombre } \\
\text { científico }\end{array}$ & $\begin{array}{l}\text { Tamaño } \\
\text { (planta) }\end{array}$ & Temporada de \\
\hline 3 & Mango & $\begin{array}{l}\text { Diarrea con } \\
\text { sangre, tos y } \\
\text { asma. }\end{array}$ & Mankru & $\begin{array}{l}\text { Mangifera } \\
\text { indica. }\end{array}$ & $\begin{array}{l}\text { Crecen hasta } 40 \\
\text { metros de altura. }\end{array}$ & Perenne \\
\hline 4 & $\begin{array}{l}\text { Uña de gato: } \\
\text { Es un especie de bejuco de } \\
3 \mathrm{~cm} \text {, de forma redonda, color } \\
\text { café, en el interior color rojizo. }\end{array}$ & $\begin{array}{l}\text { Hemorragia } \\
\text { vaginal. }\end{array}$ & $\begin{array}{l}\text { Kubamh } \\
\text { Anan }\end{array}$ & - & $\begin{array}{l}\text { Bejuco cuyo } \\
\text { grueso desarrolla } \\
3 \mathrm{~cm} .\end{array}$ & Perenne \\
\hline 5 & $\begin{array}{l}\text { Zorrillo: } \\
\text { Hierba de hasta 1m, hojas } \\
\text { elípticas, flores verdosas, } \\
\text { pétalos ausentes. } \\
\end{array}$ & Resfriado. & - & $\begin{array}{l}\text { Petiveria } \\
\text { alliacea }\end{array}$ & $\begin{array}{l}\text { Crece hasta } 1 \\
\text { metro. }\end{array}$ & - \\
\hline 6 & $\begin{array}{l}\text { Guapinol: } \\
\text { Árbol de } 6 \text { m de altura, } \\
\text { desarrolla hasta } 30 \text { metros de } \\
\text { ancho. }\end{array}$ & $\begin{array}{l}\text { Restaura la } \\
\text { debilidad. }\end{array}$ & Tip & - & $\begin{array}{l}\text { Desarrolla } \\
\text { unos } 60 \text { metros de } \\
\text { altura. }\end{array}$ & Perenne \\
\hline 7 & $\begin{array}{l}\text { Kungtitir: } \\
\text { Una hoja redonda en forma } \\
\text { de moneda, en la orilla tiene } \\
\text { cortadas, no tiene olores } \\
\text { simples. }\end{array}$ & $\begin{array}{l}\text { Para dar a luz } \\
\text { con mayor } \\
\text { rapidez. }\end{array}$ & Kungtitir & - & - & Perenne \\
\hline 8 & $\begin{array}{l}\text { Albahaca: } \\
\text { Planta aromática de hojas } \\
\text { verdes de } 15 \mathrm{~cm} \text { de alturas y } \\
\text { flores blancas. }\end{array}$ & Dolor de oído. & - & Ar habaga & $15 \mathrm{~cm}$ de altura. & Perenne \\
\hline 9 & $\begin{array}{l}\text { Guayaba: } \\
\text { Planta de cuatro metros de } \\
\text { altura, tiene hojas gruesas y } \\
\text { duras, flores blancas, tronco } \\
\text { liso de madera muy dura. }\end{array}$ & Diarrea. & Kuabris & $\begin{array}{l}\text { Psidium } \\
\text { Guajava }\end{array}$ & $\begin{array}{l}\text { Puede alcanzar } \\
\text { hasta } 4 \text { metros de } \\
\text { altura. }\end{array}$ & Perenne \\
\hline 10 & $\begin{array}{l}\text { Indio desnudo: } \\
\text { Planta de } 40 \text { metro de altura, } \\
\text { corteza lisa, color rojizo. }\end{array}$ & Susto o espanto. & Limhsi & - & $\begin{array}{l}\text { Crece hasta } 40 \\
\text { metros. }\end{array}$ & $\begin{array}{l}\text { Estación } \\
\text { lluviosa }\end{array}$ \\
\hline 11 & Tomate: & $\begin{array}{l}\text { Llagas, } \\
\text { quemadura y } \\
\text { carate. }\end{array}$ & Paumak & Lycopersicion & 1 metro de altura. & $\begin{array}{l}\text { Estación } \\
\text { primaria. }\end{array}$ \\
\hline 12 & \begin{tabular}{|l|} 
Quinina: \\
Es una especie de bejuco de \\
10 metros, se desarrolla en el \\
subsuelo, redondo color rojizo.
\end{tabular} & Diabetes. & Samalay & - & $\begin{array}{l}\text { Desarrolla } 8 \mathrm{~cm} \\
\text { redondo, rojizo. }\end{array}$ & Paumak \\
\hline 13 & $\begin{array}{l}\text { Ayote: } \\
\text { Es una especie de bejuco } \\
\text { delgado, fino, su fruta se } \\
\text { desarrolla del tamaño de } \\
\text { una sandía, hojas redondas, } \\
\text { gruesas y verdes. }\end{array}$ & Parásitos. & Mukata & Calabaza & $\begin{array}{l}10 \text { a } 15 \text { metros de } \\
\text { largo. }\end{array}$ & Apante \\
\hline 14 & Pico de pájaro: & $\begin{array}{l}\text { Llaga, tiña y } \\
\text { otras afecciones } \\
\text { superficiales. }\end{array}$ & Pisabit & $\begin{array}{l}\text { Senna } \\
\text { occidentalis }\end{array}$ & $\begin{array}{l}\text { Plantas de } 2 \\
\text { metros de altura. }\end{array}$ & Anual \\
\hline
\end{tabular}




\begin{tabular}{|c|c|c|c|c|c|c|}
\hline \multicolumn{2}{|r|}{ Tipos de Plantas } & Enfermedades & Mayangna & $\begin{array}{l}\text { Nombre } \\
\text { científico }\end{array}$ & $\begin{array}{l}\text { Tamaño } \\
\text { (planta) }\end{array}$ & $\begin{array}{l}\text { Temporada de } \\
\text { corte }\end{array}$ \\
\hline 15 & $\begin{array}{l}\text { Nancite: } \\
\text { Planta frutal de hasta } 20 \\
\text { metros, hojas pequeñas, } \\
\text { ovaladas, flor amarilla, olor } \\
\text { simple, es gruesa y escamosa. }\end{array}$ & Diarrea. & Krabu & - & $\begin{array}{l}20 \text { metros de } \\
\text { altura, } 2.5 \mathrm{de} \\
\text { diámetro. }\end{array}$ & $\begin{array}{l}\text { Se corta } \\
\text { anualmente. }\end{array}$ \\
\hline 16 & $\begin{array}{l}\text { Querosín: } \\
\text { Árbol leñoso ramado, } \\
\text { corteza aromática. }\end{array}$ & Hongos. & Sahkal & - & $\begin{array}{l}40 \text { metros de } \\
\text { altura, corteza } \\
\text { gruesa y } \\
\text { aromática. } \\
\end{array}$ & Perenne \\
\hline 17 & $\begin{array}{l}\text { Cacao: } \\
\text { Árbol, coliflor, flor y frutos } \\
\text { nacen directamente del tallo y } \\
\text { ramas, hojas anchas de } 1.5 \mathrm{~cm} .\end{array}$ & Cicatriz. & Kakan & $\begin{array}{l}\text { Del cacao o } \\
\text { cacaotero }\end{array}$ & $\begin{array}{l}\text { Árbol de } 10-12 \\
\text { metro de alto. }\end{array}$ & $\begin{array}{l}\text { Temporada } \\
\text { primaria y } \\
\text { secundaria }\end{array}$ \\
\hline 18 & Waibon: & $\begin{array}{l}\text { Diabetes como } \\
\text { reconstituyente en } \\
\text { la sangre. }\end{array}$ & $\begin{array}{l}\text { Piswal } \\
\text { Wanh }\end{array}$ & $\begin{array}{l}\text { Senna } \\
\text { occidentalis }\end{array}$ & $\begin{array}{l}\text { Plantas de dos } \\
\text { metros de altura. }\end{array}$ & $\begin{array}{l}\text { Anual o } \\
\text { perenne }\end{array}$ \\
\hline 19 & $\begin{array}{l}\text { Manzanilla: } \\
\text { Hierba anual racimosa, } \\
\text { de unos } 60 \mathrm{~cm} . \text { Hojas con } \\
\text { segmentos lineales. }\end{array}$ & Varicela. & Sisit & $\begin{array}{l}\text { Matricaria } \\
\text { curativa }\end{array}$ & $\begin{array}{l}\text { Hierba de unos } \\
60 \mathrm{~cm} .\end{array}$ & Perenne \\
\hline 20 & $\begin{array}{l}\text { Matapalo: } \\
\text { Una planta ovalada, primero } \\
\text { se identifica como una } \\
\text { especie de bejuco y se } \\
\text { desarrolla en un árbol grande, } \\
\text { corteza lisa, ralita. }\end{array}$ & $\begin{array}{l}\text { Huesos } \\
\text { fracturados. }\end{array}$ & Laka & $1-$ & $\begin{array}{l}\text { Crece unos } 60 \mathrm{~cm} \\
\text { de largo. }\end{array}$ & Perenne \\
\hline 21 & $\begin{array}{l}\text { Roble: } \\
\text { Flores blancas, por dentro } \\
\text { semillas con pelusas. }\end{array}$ & Amenorrea. & Pala & - & $\begin{array}{l}10-25 \text { metros de } \\
\text { altura. }\end{array}$ & Perenne \\
\hline 22 & $\begin{array}{l}\text { Angiosperma: } \\
\text { Planta cuyas semilla están } \\
\text { cerradas. }\end{array}$ & Diarrea liquida. & Pisit & - & $\begin{array}{l}\text { Una planta casera } \\
\text { de } 4 \text { a } 5 \text { metro de } \\
\text { altura. }\end{array}$ & Perenne \\
\hline
\end{tabular}

\section{APLICACIÓN DE PLANTAS MEDICINALES A DIFERENTES TIPOS DE ENFERMEDADES PRIMARIAS}

Para este apartado se presenta la aplicación de plantas medicinales en diez enfermedades primarias y comunes en las comunidades tuahkas. Se explica sus aplicaciones y dosis, dependiendo de las enfermedades. Las aplicaciones se realizan a través de plantas medicinales.

\section{Basah (diarrea)}

Preparación y dosis: Se pone a cocer, por 40 minutos, unos cuantos trocitos de la corteza de guayaba, hasta obtener un líquido bastante fuerte color rojizo. A los niños se les da dos cucharadas cada tres horas; a los adultos, $1 / 2$ taza cada dos horas.

Recomendación: Para combatir la deshidratación y los golpes de calor, tomar dos vasos de agua de arroz al día, después de hervir, dejar enfriar y colarlo.

\section{Tining (vómitos)}

Preparación y dosis: Se utiliza una buena cantidad de planta centavito; se machaca, se cuela con agua limpia, como si fuese algún fresco; en seguida se bebe un litro diario por tres días.

Recomendación: En esta aplicación no se prohíbe la dieta.

\section{Ûtrangh (dolor de estómago)}

Preparación y dosis: Se utiliza el bejuco de piswalwanh, se 
corta tres pedacitos de tres centímetros y se rajan en cuatro partes. Luego se ponen a cocer por 45 minutos hasta obtener bastante solidez; después se deja reposar para enfriar, se vierte en un frasco de $2 \frac{1}{2}$ litros y se guarda por quince días. Cada tres horas se bebe $1 / 2$ taza hasta terminar el contenido.

Recomendación: Se recomienda también la utilización de manzanilla la cual favorece las digestiones difíciles y ayuda a expulsar los gases del aparato digestivo.

\section{Tunrangh (dolor de cabeza)}

Preparación y dosis: Se procede a la preparación con las siguientes plantas: la dormilona, pico de pájaro, y escobillo. Se extraen las hojas y se machaca bien, luego se calienta con una hojita en el fuego, después se aplica frotando la parte afectada de la cabeza. La hoja machacada se aplica como cataplasma en la parte donde duele.

Recomendación: Una vez aplicado el remedio, no se debe salir al sereno ni mojarse, por un periodo de ocho días o más.

\section{Uhuh (tos)}

Preparación y dosis: Se pone a cocer, de cuatro a cinco minutos, tres raíces de culantro y un puñito de hojas de eucalipto, se mezclan los dos remedios y posteriormente se deja que se enfríe. Tomar luego $1 / 2$ taza varias veces al día sin medida.

Recomendación: También se recomienda el jugo de limón ácido, con sal y agua tibia.

\section{Utbanbil (parásitos)}

Preparación y dosis: Se cuecen siete hojas grandes y un puño de hojas tiernas de jocote durante veinte minutos. Luego tomar $1 / 2$ tacita cada cuatro horas por un día y medio.

Recomendación: Se puede utilizar también la fruta seca de ayote cocido y tomar $1 / 2$ taza cada seis horas.

\section{Taprangh (dolor de oído)}

Preparación y dosis: Machacar tres hojas de albahaca y colarlas con un trapo limpio; luego vertir en el oído dos gotitas; posteriormente se coge un pedazo de algodón mojado en el líquido y se introduce escasamente en el oído y se deja tapado. Se saca hasta el día siguiente.

Recomendación: También se recomienda para esta enfermedad el perejil. Se fabrica una pequeña pelotita, se humedece con aceite de coyol, se agrega un poquito de sal y se introduce mojado en el oído.

\section{Anrangh (dolor de muela)}

Preparación y dosis: Para este tratamiento se recomienda la leche de chilamate. Se recoge en un frasco y luego, con un pedacito de algodón o con otro material, se moja y posteriormente se introduce con mucha calma en el diente afectado.

Recomendaciones: Se debe preparar con mucha anticipación.

\section{Dinut (mareos)}

Preparación y dosis: Corteza de guapinol cocido con leche de vaca; reconstituye y quita el mareo y otras enfermedades.

\section{PORTADORES CULTURALES DE LA INVESTIGACIÓN}

Roger Stiven Sailas • Sonia Juwith • Leonel Franklin • Aquilino Melendez M. • Jacinto Marcos Taylor • Faustina Bendlis Jhony • Silvia Bendlis • Maritza López Montiel • Manuela Stiven Sailas • Paladino Fenly Penn• Saida washintong • Rivas Fedrick Isidro • Evans Penn Taylor • Cornelio Fenly Penn • Hayde Penn Taylor • Elna Dixon Bendlis • Herminia Castillo $\bullet$ Indalecio Scoth $\bullet$ Roberto Jhony Somons • Cedy Penn Morales.

\section{REFERENCIAS BIBLIOGRÁFICAS.}

Hermandad de mujeres indígenas (1997). San José, Costa Rica.

Talamanca y Cabagra. (2011). Narraciones Bribris. San José pag.48.

Ley No 759. Ley de medicina tradicional ancestral, Gaceta Diario oficial 04/07/2011 pág. 123.

La Rousse (2011).Diccionario de la lengua española

www.organizacion mundial de la salud. (2007). Bajado el 10/10/11)

www.costaricaspinalcare.com (2006). Bajado el 10/1O/11) 